\title{
Response of river flow regime to various climate change scenarios in Ganges-Brahmaputra-Meghna basin
}

\author{
Rajib Kamal $^{1, ~ *, ~ M . ~ A . ~ M a t i n ~}{ }^{1}$, Sharmina Nasreen ${ }^{2}$ \\ ${ }^{1}$ Department of Water Resources Engineering, Bangladesh University of Engineering and Technology, Dhaka, Bangladesh \\ ${ }^{2}$ Bangladesh Water Development Board, Dhaka, Bangladesh
}

\section{Email address:}

rajibkamal@wre.buet.ac.bd(R. Kamal)

\section{To cite this article:}

Rajib Kamal, M. A. Matin, Sharmina Nasreen. Response of River Flow Regime to Various Climate Change Scenarios in Ganges-Brahmaputra- Meghna Basin. Journal of Water Resources and Ocean Science. Vol. 2, No. 2, 2013; pp. 15-24. doi: $10.11648 /$ j.wros.20130202.12

\begin{abstract}
The potential climatic variability over Ganges-Brahmaputra-Meghna (GBM) basin like alterations in precipitation and temperature are expected to have a significant impact on the natural flow regime of its rivers. The Lower Meghna River, being a major drainage outlet of the basin, is likely to be affected by such variability and hence its response to climate can be studied through the use of plausible scenarios of climate change. In this study, an artificial neural network (ANN) model, based on future climate projections of HadCM3 GCM, was constructed to examine the potential changes in the river flow regime assuming that climate tend to change as per the SRES scenarios A1B, A2 and B1. The results showed a trend of increasing monsoon flows for these scenarios during the periods of 2020s, 2050s and 2080s with a projected shift in the seasonal distribution of flows. Examining the monthly projected flows for different scenarios and comparing with the observed condition, it was found that the peak flow may increase $4.5-39.1 \%$ in monsoon and the dry period low flows may drop by $4.1-26.9 \%$ indicating high seasonality as a result of climate change. Due to seasonal variation of precipitation and temperature, i.e., excess precipitation in monsoon and lack of precipitation along with higher temperature in the dry season, the flood peaks are likely to shift towards earlier months and the rate of change of flows during the rising and recession of flooding would be much higher compared to current state of the river. These results also indicate the exacerbation of flooding potential in the central part of Bangladesh due to the largest increase of peak flows during monsoon.
\end{abstract}

Keywords: Climate Change, GBM Basin, Lower Meghna River, Flow Regime

\section{Introduction}

Rivers take up an important place when investigating the climate as a whole. For the last century, natural flow regimes of rivers have been modified continuously by different anthropogenic factors such as dam construction, water withdrawals for irrigation, electricity production, manufacturing, domestic purposes and others[1]. Many rivers have also been artificially modified by channelization, embanking, straightening, widening or deepening with further impacts on flow characteristics. Now-a-days climate change constitutes another factor for flow regime alteration and will interact with other anthropogenic flow modifications. The variation of river flow depends on several physical and hydrological processes of a basin and hence is likely to be affected by the magnitude and direction of climate change. The anticipated change in climate is likely to lead to an intensification of the global hydrological cycle and to have a major impact on regional water resources system. The Fourth Assessment Report (AR4) of Intergovernmental Panel on Climate Change (IPCC) mentions with high likelihood that the observed and projected increases in temperature and precipitation variability are the main causes for the reported and projected impacts of climate change on water resources, resulting in a significant impact on a river basin and associated river systems[2]. Hence, it is important to identify the response of river flow regime to climate change because such changes have significant environmental and socio-economic implications for planning and sustainable water resources management of a basin.

The five components of flow - magnitude, frequency, duration, timing and rate of change affect the natural regime and dynamics of rivers directly and indirectly. Among them the quantity and timing of river flow are 
critical components to water availability, water quality and the ecological integrity of a river basin[3]. River flows respond to changes in basin runoff which is more sensitive to changes in precipitation and evaporation than other climate variables. For a catchment with a low runoff ratio, the effect of a $10 \%$ reduction in precipitation may range from a $50 \%$ reduction in river discharge with no direct $\mathrm{CO}_{2}$ effect, to a $70 \%$ increase in discharge with a maximum direct $\mathrm{CO}_{2}$ effect[4]. Assuming no changes in land use, long term changes in basin runoff are largely driven by changes in precipitation and those climatic factors controlling evaporation, in particular, temperature. Variation in temperature also affects the melting of glacier-snows in the upper headwater region. Changed basin water balance due to variation of precipitation and glacier melts may alter the discharge hydrographs of rivers, and such alterations may cause significant changes in the flow regime of a river. Since the principal climatic factors that control the streamflow are precipitation and temperature, the response of river regime to climate can be studied through the use of plausible scenarios of climate change.

In the present study, the river flow response to changes in climate was evaluated by considering the Lower Meghna River as a case study. The river, being a major drainage outlet of the Ganges-Brahmaputra-Meghna (GBM) basin, is one of the largest rivers in the world in terms of river flow. The river carries the combined flows of Ganges, Brahmaputra and Upper Meghna which receives over 90 percent of the water from the GBM basin[5]. The GBM basin is likely to be sensitive to potential climate change impacts where the hydrological regime is strongly influenced by the variables like precipitation, temperature or evaporation. A modification of the prevalent climate can considerably affect this regime and induce important impacts on the associated river systems like the Lower Meghna River. To analyze such response, a data-driven artificial neural network (ANN) model was developed using climate-flow data. The objective of this study was to assess the potential impacts of future climate scenarios on river at basin scale and to examine potential changes in flow regime assuming that the climate tend to change as per the plausible scenarios mentioned in the Special Report on Emission Scenarios (SRES) given by IPCC.

\section{The Ganges-Brahmaputra-Meghna River System}

The Ganges-Brahmaputra-Meghna basin is located between 22 degree 3.5 minutes and 31 degree 50 minutes north latitudes and 73 degree 10.5 minutes and 97 degree 53 minutes east longitudes[5]. The basin is characterized by diversified geographic features covering five countries China, India, Nepal, Bhutan and Bangladesh of the South Asian region. Topographically it is extended in three characteristic areas: the Hindukush Himalaya, the Ganges Delta and the Peninsular Basin of central India (Fig. 1). The mountainous areas of Himalaya and some hilly regions of central and eastern India are the major sources of the rivers in this region. The three main rivers - the Ganges, the Brahmaputra and the Meghna cover 907,000 sq. km, 583,000 sq. $\mathrm{km}$ and 65,000 sq. $\mathrm{km}$ areas of the basin respectively[6].

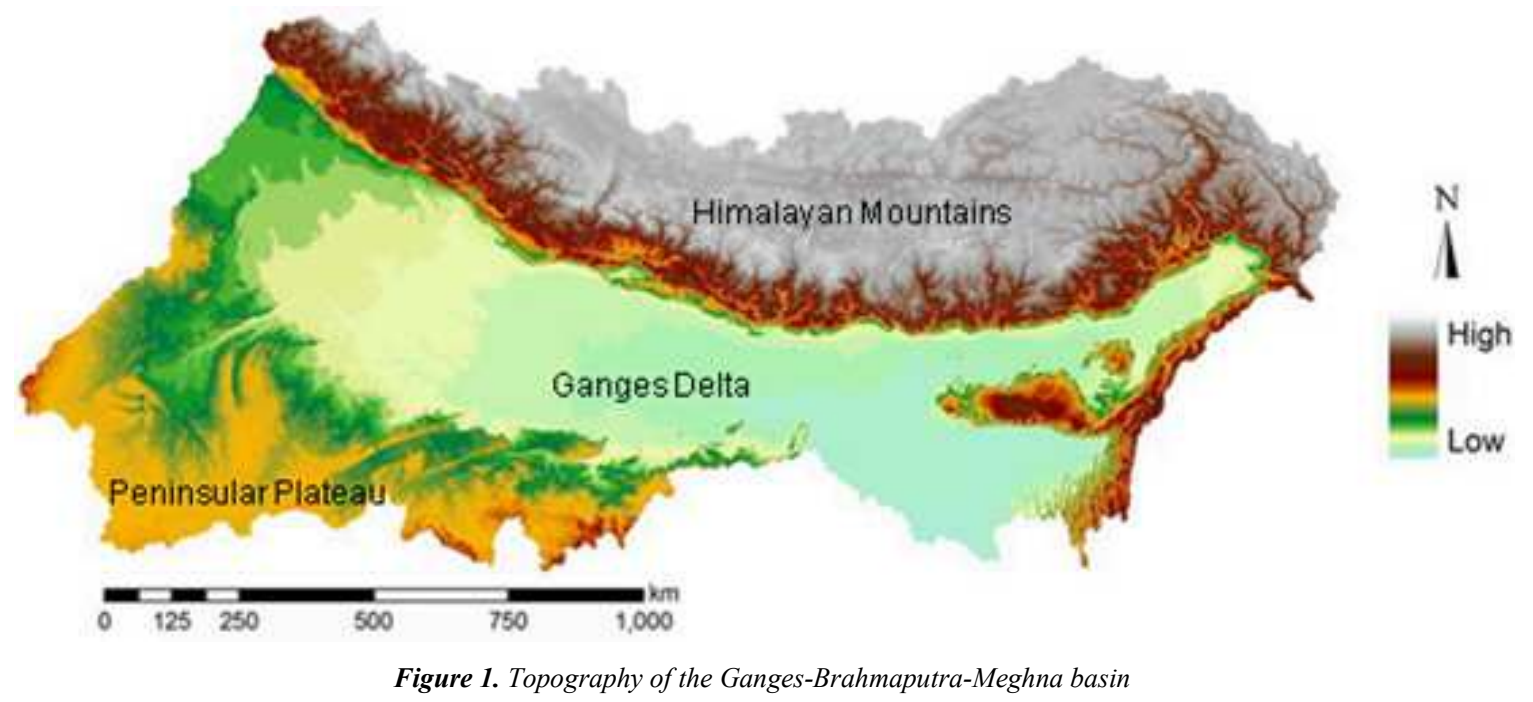

The headwaters of the Ganges and Brahmaputra originate in the Tibetan China area of the Himalayan Mountain range. The Ganges originates in the Uttaranchal Himalayas after the confluence of six rivers, flows south-west into India after the confluence of six rivers, turns southeast joining its major tributaries and enters Bangladesh through the western border (Fig. 2).
Originating from the great glacier mass of Chema-Yung-Dung in the Kailas range of southern Tibet, the Brahmaputra traverses south and west into India and then directs south into Bangladesh. The Meghna rises in the Manipur Hills of northeast India, flows west and is formed inside Bangladesh above Bhairab Bazar by the combination of the Surma and Kushiyara rivers. It meets the combined 
flow of Ganges and Brahmaputra (known as the Padma) near Chandpur and is drained into the Bay of Bengal through the Lower Meghna River. The combined discharge of these three major rivers is among the highest in the world. While the discharge within the Lower Meghna (the part downstream of the confluence near Chandpur) typically varies between $8,000 \mathrm{~m}^{3} / \mathrm{s}$ in February-March and $100,000 \mathrm{~m}^{3} / \mathrm{s}$ in July to September, the peak discharge exceeds $120,000 \mathrm{~m}^{3} / \mathrm{s}$ in the year of severe flood[7]

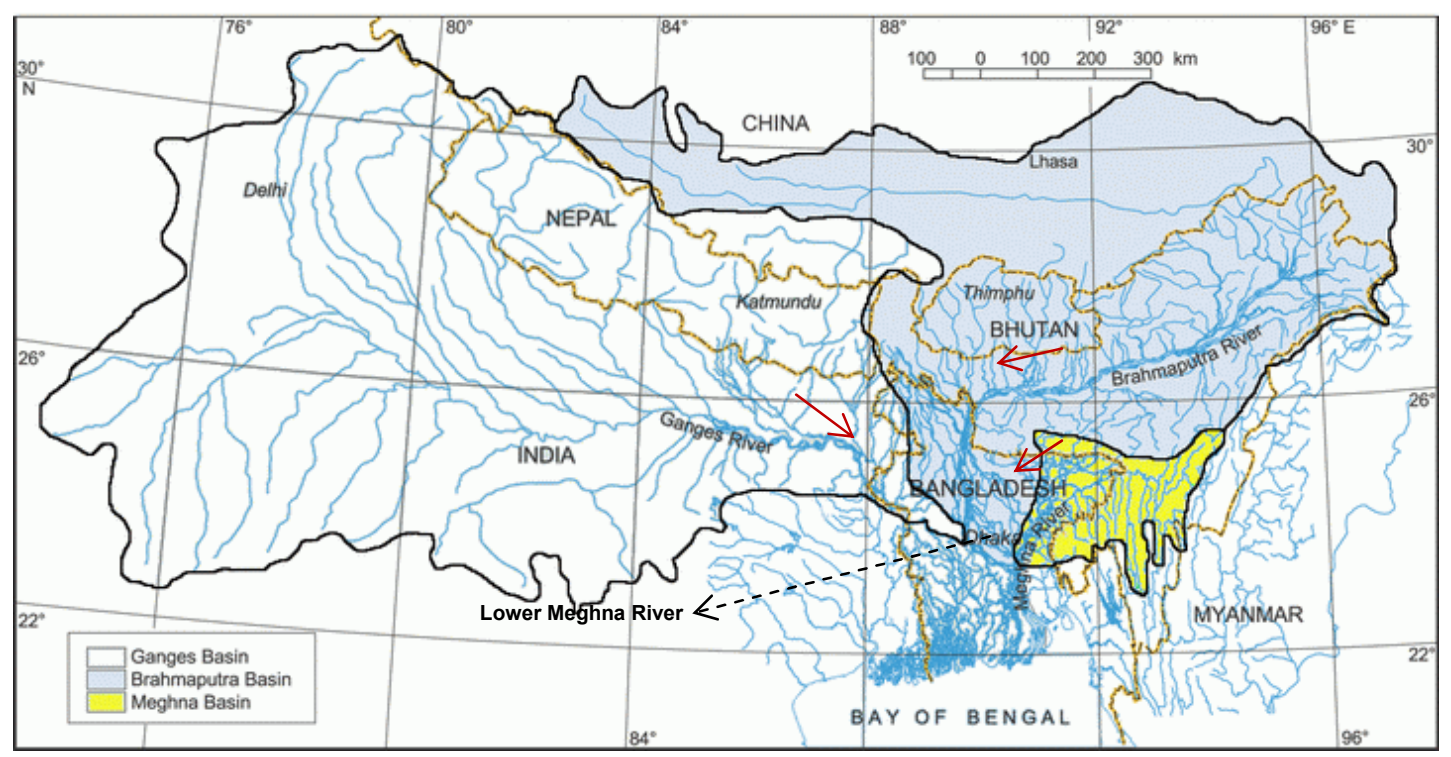

Figure 2. The GBM basin with principle channels of Ganges, Brahmaputra and Meghna

\section{Climate Change Scenarios}

Among the major river systems of the world, the impact of climate change on the Ganges-Brahmaputra-Meghna basin is expected to be particularly strong[8]. The water supply of GBM rivers is dependent on the rains brought by the southwesterly monsoon winds as well as on the flow from melting Himalayan snows. The Ganges basin is characterized by low precipitation in the northwest of its upper region and high precipitation in the areas along the coast. Annual rainfall ranges from $760 \mathrm{~mm}$ at the western end to more than $2000 \mathrm{~mm}$ at the eastern end. The Brahmaputra basin, excluding the Tibetan portion, forms high precipitation zone and dry rain shadow areas as an integral part of the southeast Asian monsoon regime with a mean annual rainfall of $2600 \mathrm{~mm}$. The world's highest precipitation area is situated in the Meghna basin[5, 9]. When intensive rainfall occurs simultaneously over these basins, the combined runoff causes high floods in the downstream rivers. Regional variation of temperature is also significant in these basins. Mean temperatures in the Himalayas ranges are $10-15^{\circ} \mathrm{C}$. The temperature of other parts of the basin is much milder, with highs ranging from $23{ }^{\circ} \mathrm{C}$ to $26{ }^{\circ} \mathrm{C}$ and lows averaging from $8{ }^{\circ} \mathrm{C}$ to $14^{\circ} \mathrm{C}[5]$. Variation in temperature also affects the basin water storage through melting of Himalayan snows and evaporation. Therefore any climatic variability like alterations in precipitation and temperature are hypothesized to be responsible for the streamflow variation within the GBM rivers, both in terms of magnitude of flow and in timing of onset, peak and recession of flooding.
To assess the response of flow regime of Lower Meghna River to changes in GBM basin climate, it is necessary to construct future climate projections as per IPCC guidelines. Currently General Circulation Models (GCMs) are the most credible tools available for simulating the response of the global climate system to increasing greenhouse gas concentrations and to provide estimates of climate variables such as temperature, precipitation etc. For the present study, the transient HadCM3 GCM, developed by Hadley Center for Climate Prediction and Research, were used for the projected emission scenarios of SRES A2, A1B and B1. These scenarios represent a plausible range of conditions where A2 corresponds to relatively unconstrained growth in global emissions and B1 corresponds to reduction of global emissions over the next century[10]. A1B assumes a balanced energy adoption between fossil fuels and other energy sources to drive the expanding economy and has been used in many impact studies for Bangladesh.

\section{Methodology}

In this study, the response of Lower Meghna River flow regime was evaluated following a linear approach - feeding climatic inputs into a system model, comparing system performance with observed conditions and estimating impacts with alternate climate inputs. Using artificial neural network (ANN) technique, a model was developed to approximate the relation between the observed historical precipitation, temperature and river flow data and to estimate the future river flows driven by anticipated changes in climate according to the SRES scenarios. 


\subsection{Data Collection and Processing}

The observed temperature and precipitation data over the GBM basin were obtained from the global database developed by Climate Research Unit (CRU). The CRU provides gridded dataset of monthly precipitation and temperature[11]. These data covering the GBM basin were collected for the period of 1975 to 1998. The projected temperature and precipitations of HadCM3 GCM model for different periods were retrieved from the IPCC Data Distribution Center (DDC). This model has a spatial resolution of $2.5^{\circ} \times 3.75^{\circ}$ which produces a surface representation of about $417 \mathrm{~km} \times 278 \mathrm{~km}$. To estimate the future streamflows of the river, 30-year averaged model projections were used for three time slices namely 2020s for 2010-2039, 2050s for 2040-2069 and 2080s for 2070-2099 with reference period of 1961-1990. The basin averaged changes in precipitation and temperature with respect to this reference period are shown in Fig. 3. This figure depicts that precipitation increase is maximum in the month of July for most of the scenarios. However, scenario B1 in 2050s exhibits a different pattern due to lesser increase of temperature in July. The variation of temperature change is consistent for all the scenarios.

$\longrightarrow 2020$ s $--\cdot-2050 s \quad-\cdot 2080$ s
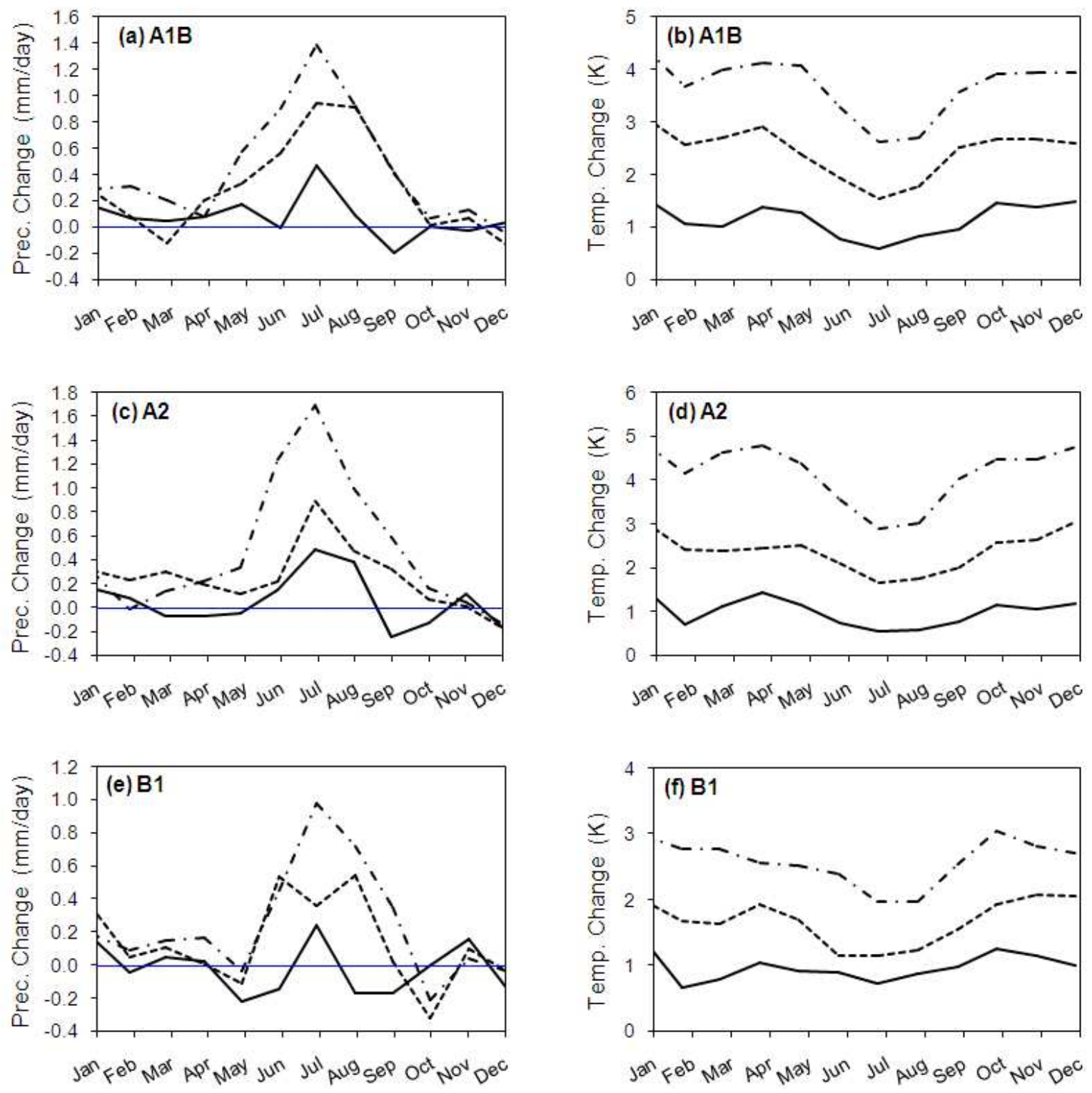

Figure 3. Basin averaged changes in monthly precipitation and temperature for SRES scenarios A1B, A2 and B1

Various hydrographic and river flow data was collected from Bangladesh Water Development Board (BWDB) for the period of 1975 to 2008. The river discharges at Chandpur were derived form 1-D model HEC-RAS by incorporating discharge of Padma and Upper Meghna River and were employed as observed streamflow records to validate the 
simulated outputs obtained from the ANN.

\subsection{Setting of Basin Grids}

To identify the implicit connection between the river flow regime and the climate variability of GBM basin and to understand the nonlinear complex interactions among them, the study area was divided into total of 32 grids of resolution $2.5^{\circ} \times 3.75^{\circ}$ (latitude by longitude). In order to maintain consistency among the grids and the resolution of the GCM projections, the observed precipitation and temperature data was also converted in the same resolution. United States
Geological Survey produced drainage maps of GBM basin of 0.5 degrees grids along with major river networks of the region[12]. These grids along with superimposed flow network was modified and simplified into $3.75 \times 2.5$ degree resolution in order to match with the climate inputs over GBM basin. Fig. 4 shows both the flow network and grids of GBM basin with the polygon of Bangladesh. Flow network was constructed in such a way that it carries water (runoff) from one cell to the next discharging cell based on the drainage directions.

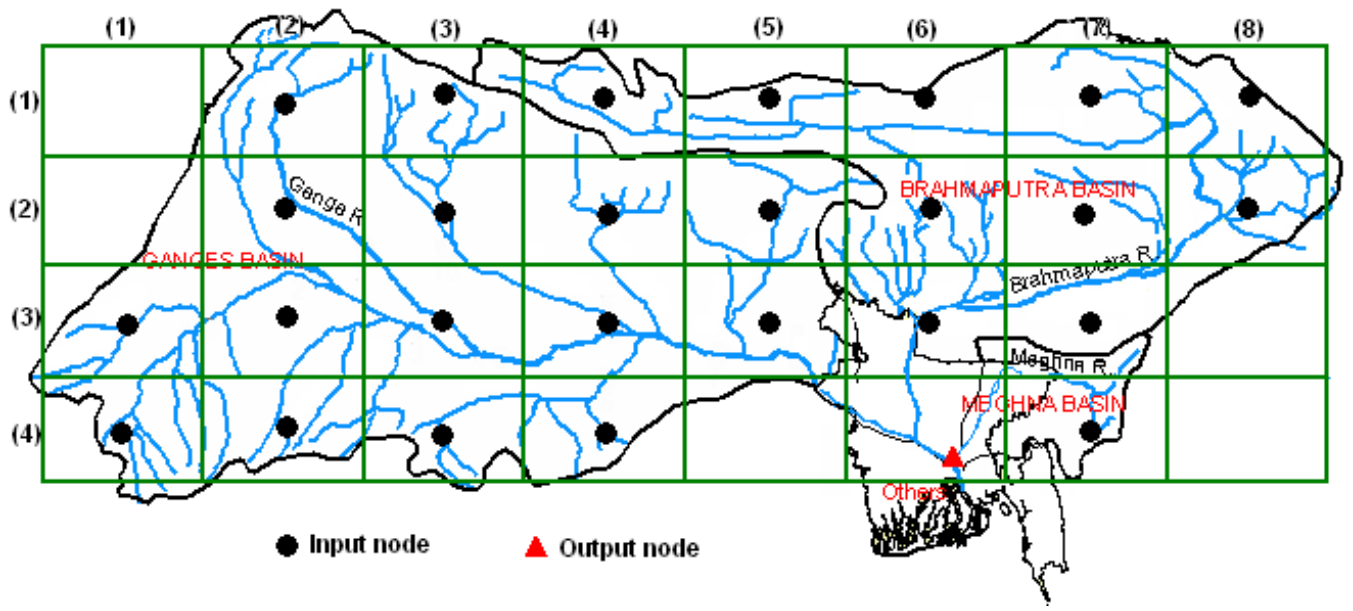

Figure 4. Simplified GBM grids with flow network and input-output nodes of ANN model

In a firm ANN architecture, key variables must be introduced and unnecessary variables must be avoided in order to prevent confusion in training (calibration) and validation process. The input node for the present study was the precipitation and temperature over GBM basin. Based on the flow direction on the grids shown in Fig. 4, a total of 26 out of 32 grids were selected as input nodes. 6 grids (grid number $11,12,54,64,83$ and 84 ) do not contribute to the flow and hence were excluded from the analysis. Assuming all the precipitation over GBM contributes to the basin runoff and the resultant combined flow drains out through the Ganges, Brahmaputra and Meghna River system, the Lower Meghna River can be considered as the outlet of the basin. Therefore the discharge of the river at Chandpur was taken as the output node of the neural network model. Both the input and output nodes, i.e. temperature, precipitation and discharge, were the input variables of the model.

\subsection{The Artificial Neural Network Model}

A data-driven artificial neural network model was developed to evaluate streamflow responses of Lower Meghna River to climate variations of GBM basin. Although the application of physical or conceptual models could have been a better representation of the hydrological features of the basin, ANNs can be considered an alternate to such models because of its ability to simulate nonlinear complex system without detailed watershed data. Therefore in recent years, many researchers have demonstrated the successful application of the ANN in basin wide streamflow forecasting[13-15]. For the present study, the basin was schematized as a system, whose inputs were precipitation and temperature (which influence the evaporation and snowmelt) and its output was the river flow. Then the neural network model can be written as -

$$
y=f\left(u_{j}\right) \text { with } u_{j}=\sum w_{i} x_{i}-\theta_{j}
$$

Here, $x_{i}=$ inputs to flow, $w_{i}=$ weight of $x_{i}$ and $\theta_{j}=$ critical value. The output of node $j, y_{j}$, can be obtained by computing the activation function that determines the response of a node to the total input signal it receives. The most commonly used activation function is the sigmoid function[16]. Historical analyses of the streamflow (Q), precipitation $(\mathrm{P})$ and temperature $(\mathrm{T})$ variations in the GBM river basin indicated that its streamflow lagged the precipitation by one month[6]. This leads to the relation of $Q$ at time $(\mathrm{t})$, treated as a function of $\mathrm{P}$ and $\mathrm{T}$ at time $(\mathrm{t})$ and $(\mathrm{t}-1)$ as follows -

$$
Q(t)=f\left(P_{t}, P_{t-1}, T_{t}, T_{t-1}\right)
$$

In this study, feedforward neural network technique was employed as this is closely related to statistical models that are a data-driven approach and more suited for forecasting applications[17]. To determine an appropriate set of weights in (1), the model was trained using the error backpropagation algorithm and momentum was used for speeding convergence to a minimum error. The calculation 
was done using MATLAB software. A total of 26 nodes representing monthly temperature and precipitation and a single node representing monthly discharge were used in the input and output layer of the model respectively. The number of hidden layers and their nodes depend on the performance of the model and was determined by trial and error basis for the present study. Due to the nature of the sigmoid function, all input data of the model were normalized to an internal representation between 0 and 1 in order to receive equal attention in the training of the model.

\subsection{Model Training and Validation}

To determine the neural network architecture that best matches the desired response and to check the accuracy of the model, the available data were divided into two subsets: a training period from 1975 to 1990 and a validation period from 1991 to 1998 .In this study, five trials were performed to obtain the best network that predicts discharge from the temperature-precipitation inputs. For each trial, different networks were used by changing number of hidden layers, number of processing elements or nodes in each hidden layer, number of iterations etc. During training, initial weights were randomly generated and the goal for error criterion was 0.0001 . These were adjusted based on the mean squared error (MSE) between the ANN outputs and the observed discharges and continued until a weight space was found, which results in the minimum MSE and best overall prediction of discharge. For all the trials, the calibrated networks were verified for the period of 1991 to 1998 by imposing the monthly temperature-precipitation data that were not used during training. This process was guided by various statistical indicators such as correlation coefficient $\left(\mathrm{R}^{2}\right)$, root mean square error (RMSE), mean absolute error (MAE) and mean relative error (MRE) between observed and simulated monthly discharge. The results of training and validation of the model are summarized in Table 1.

Table 1. Summary of the model training and validation

\begin{tabular}{cccccccc}
\hline Trial No. & $\begin{array}{c}\text { No. of Hidden } \\
\text { Layers }\end{array}$ & $\mathbf{R}^{\mathbf{2}}$ & RMSE & $\mathbf{R}^{\mathbf{2}}$ & RMSE & MAE & MRE \\
\hline 1 & 3 & 0.857 & 6937.2 & 0.723 & 10405.8 & 5493.4 & 0.349 \\
2 & 5 & 0.878 & 4754.3 & 0.720 & 8385.2 & 5451.1 & 0.359 \\
3 & 5 & 0.917 & 4355.5 & 0.749 & 8091.9 & 5427.4 & 0.316 \\
4 & 7 & 0.895 & 4031.3 & 0.742 & 7310.7 & 5033.0 & 0.213 \\
5 & 10 & 0.928 & 3148.4 & 0.806 & 7548.5 & 4338.2 & 0.144 \\
\hline
\end{tabular}

From the table it appears that the optimal network topology resulted in trial 5 of one output, ten hidden-layer neurons with $\mathrm{R}^{2}$ of 0.928 and RMSE of $3148.4 \mathrm{~m}^{3} / \mathrm{s}$ in the training period. For the validation period from 1991 to 1998 , the simulated streamflows were close to the observation with a $\mathrm{R}^{2}$ value of 0.806 and absolute error of the monthly mean discharge of $4338.2 \mathrm{~m}^{3} / \mathrm{s}$, merely $13 \%$ of the monthly mean value. However, the model systematically underestimates the observed streamflow by an average of $1330 \mathrm{~m}^{3} / \mathrm{s}(4 \%)$. Fig. 5 shows the measured and simulated monthly discharge record for the Lower Meghna River from the period of 1975 to 1998 .

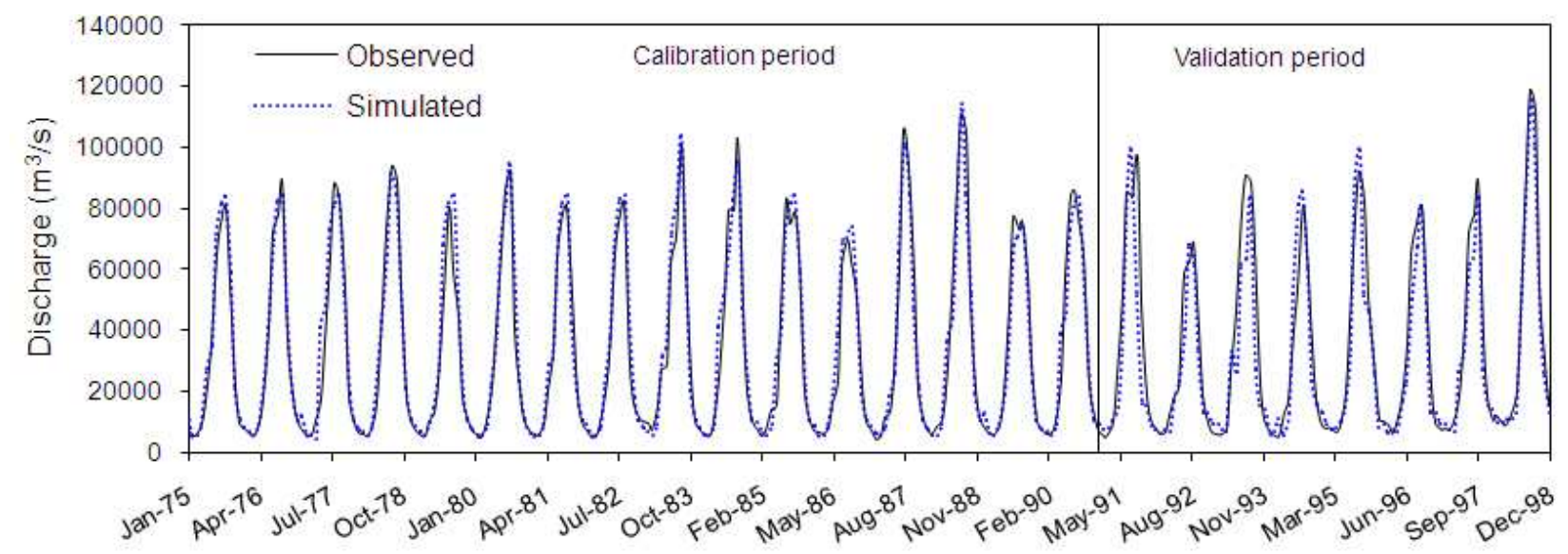

Figure 5. Comparison between observed and simulated discharge during training and validation

From the figure it is evident that the model is able to capture the rising and falling limbs of hydrograph, i.e., it predicts flow for both wet and dry season with considerable accuracy and deviations are hardly visible when looking at the seasonal pattern. These results suggest that the developed artificial neural network model is reliable to describe the hydrological processes of the basin and to address their effect on the flow variations as well as overall flow regime of the river. 


\section{Results and Discussion}

The developed neural network model was employed to describe the hydro-climate of GBM basin and to examine the influence of precipitation and temperature change on the river flow regime. Fig. 6 shows the ANN model results of projected flows of Lower Meghna River under HadCM3 SRES scenarios A1B, A2 and B1 for the periods of 2020s, 2050 s and 2080s. To compare the streamflow variation, the 30-year average of 1975-2004 was considered as the observed base condition which represents the current state of the river.
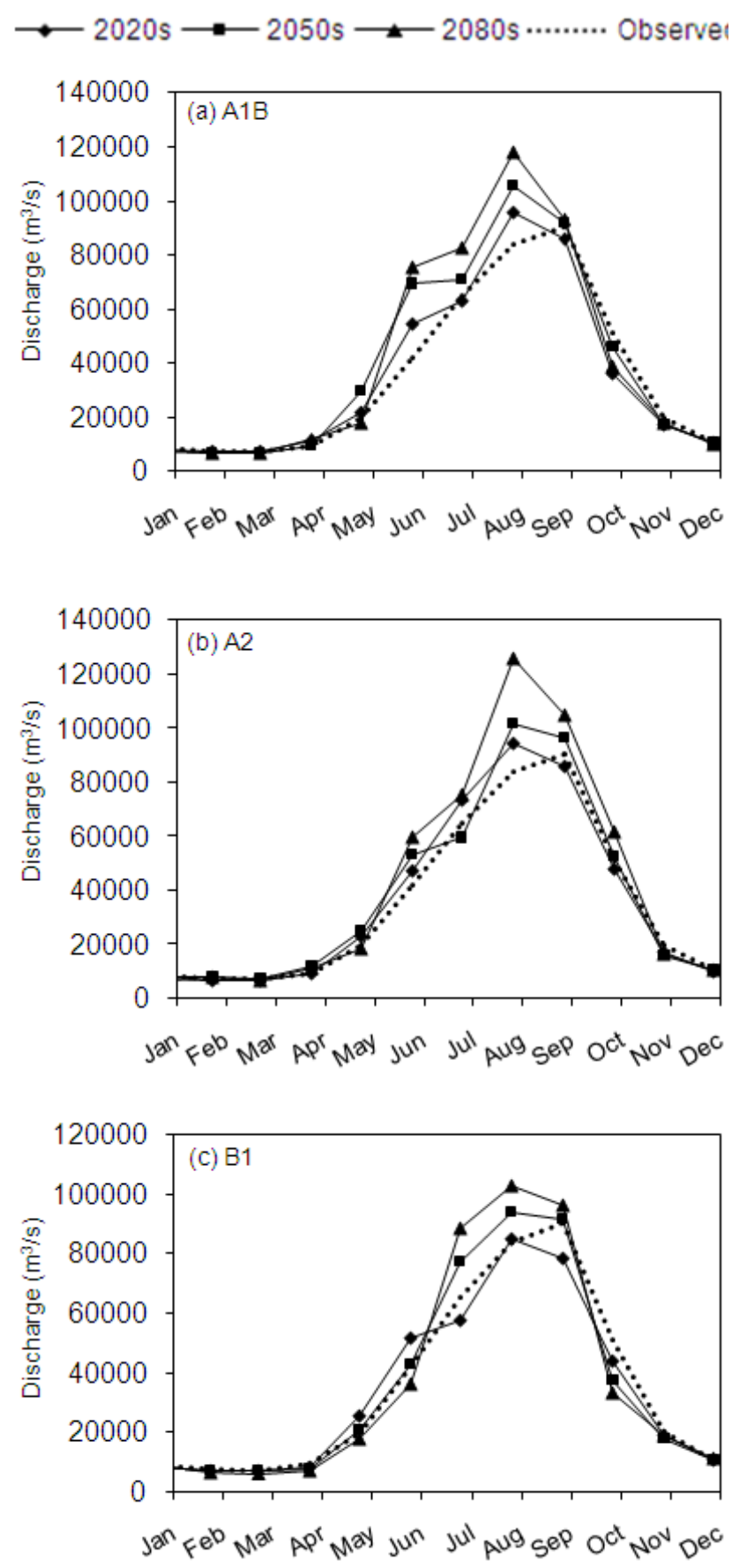

Figure 6. Projected streamflows for different climate change scenarios
The model projected streamflows of the river show that the discharge in monsoon increases progressively for the periods of 2020s, 2050s and 2080s for scenarios A1B and A2. For scenario A1B (Fig. 6a), maximum discharge was found as $96009 \mathrm{~m}^{3} / \mathrm{s}, 105586 \mathrm{~m}^{3} / \mathrm{s}$ and $118271 \mathrm{~m}^{3} / \mathrm{s}$ for the projected periods respectively which are $6.1,16.7$ and $30.7 \%$ higher than the observed condition. The rising limbs of the hydrographs tend to shift leftward indicating the occurrence of early floodwaters due to increase of precipitation in the premonsoon (upto 13\% in May and 22\% in June at 2080s) as seen from Fig. 3a. As a result of higher increase of summer-winter temperature than monsoon (Fig. 3b), the effect of evaporation becomes more pronounced than glacier snowmelt and hence the dry period low flows can decrease by $7.1,6.3$ and $16.8 \%$ respectively.

Similar trend is also observed for scenario A2 (Fig. 6b) with maximum streamflows of $94539 \mathrm{~m}^{3} / \mathrm{s}, 101730 \mathrm{~m}^{3} / \mathrm{s}$ and $125835 \mathrm{~m}^{3} / \mathrm{s}$ which are $4.5,12.4$ and $39.1 \%$ higher compared to observed condition. In this case, the peak flow in $2080 \mathrm{~s}$ are maximum compared to other scenarios due to maximum increase in precipitation (upto $26 \%$ in July at 2080s) during pre-monsoon (Fig. 3c). The discharge hydrograph becomes wider and the falling limbs tend to shift towards right. This prolonged floodwater is caused mainly by the increase in precipitation in September-October (about 10\% in 2080s). The flow may reduce $12.5,4.1$ and $19.3 \%$ respectively during the dry months of the projected periods.

On the other hand, peak streamflow in monsoon for scenario B1 (Fig. 6c) decreases 6.5\% in the 2020s but increases $3.5 \%$ in $2050 \mathrm{~s}$ and $13.7 \%$ in $2080 \mathrm{~s}$. For these periods, the maximum discharge can be found as $84611 \mathrm{~m}^{3} / \mathrm{s}$, $93672 \mathrm{~m}^{3} / \mathrm{s}$ and $102830 \mathrm{~m}^{3} / \mathrm{s}$ respectively. Due to lack of precipitation and moderate temperature change in summer-winter dry periods (Fig. 3e and 3f), flow in the dry periods decreases $11.4 \%, 18 \%$ and $26.9 \%$ for the stated periods. Hence the streamflows are more concentrated within the shorter span of monsoon resulting in longer periods of low flows in the river due to climate change.

The projected streamflows also indicate that the variations of flows are much higher in monsoon period than the summer-winter dry season when compared with the observed condition of the river. For all the three scenarios the streamflows increases considerably during the period of July -August-September. Fig. 7 shows the comparative variation of high flows for scenarios A1B, A2 and B1 for different time slices. In 2020s, the high flows decrease due to lack of monsoon precipitation for scenario B1 but increases for $\mathrm{A} 1 \mathrm{~B}$ and $\mathrm{A} 2$. Afterwards, the high flows increase progressively in $2050 \mathrm{~s}$ and $2080 \mathrm{~s}$ for all the scenarios. In comparison, the peak flows in 2020s and 2050s are maximum for scenario A1B, while in 2080s the largest peak is found for scenario A2. This is due to the fact that as the temperature rises with time, the contribution from snowmelt base flow reduces and the streamflows become more responsive to precipitation increase which is maximum for scenario A2 in 2080s. The rise of peak flows may result in severe floods of high intensity in the Lower Meghna River. 
Due to the largest increase of flood peaks in August-September, a large area, particularly the central part of Bangladesh, may be inundated. Such effect will deteriorate the situation of a flood prone country like Bangladesh.

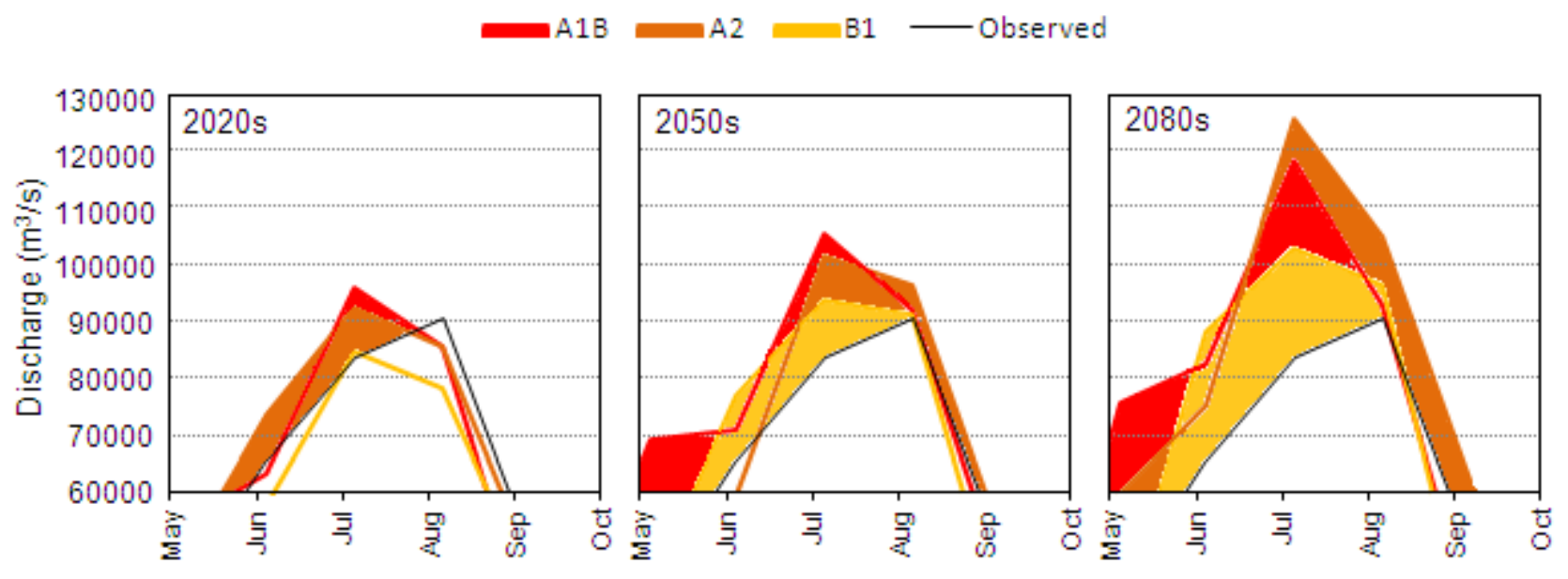

Figure 7. Increase of high flows for different scenarios compared to observed condition

The variation of flow during the dry and wet periods, specially the high flows in monsoon, affects the various components of river flow regime and alters the flood characteristics. These changes in flow characteristics such as timing of peak flow and its onset and recession under different climate scenarios are shown in Table 2.

Table 2. Hydrograph characteristics for the projected river flows

\begin{tabular}{|c|c|c|c|c|c|c|}
\hline \multirow[b]{2}{*}{ Scenario } & \multirow[b]{2}{*}{ Period } & \multirow{2}{*}{$\begin{array}{c}\text { Timing of Peak } \\
\text { Flow }\end{array}$} & \multicolumn{2}{|c|}{ Rising Limb } & \multicolumn{2}{|c|}{ Falling Limb } \\
\hline & & & Start of onset & $\begin{array}{c}\text { Gradient } \\
\left(\mathrm{m}^{3} / \mathrm{s} / \text { month }\right) \\
\end{array}$ & End of recession & $\begin{array}{c}\text { Gradient } \\
\left(\mathrm{m}^{3} / \mathrm{s} / \text { month }\right)\end{array}$ \\
\hline \multirow[t]{2}{*}{ Observed } & - & Sep & May & 21555 & Nov & 35171 \\
\hline & $2020 \mathrm{~s}$ & Aug & Apr & 20506 & Nov & 34154 \\
\hline \multirow[t]{3}{*}{$\mathrm{A} 1 \mathrm{~B}$} & $2050 \mathrm{~s}$ & Aug & Apr & 23234 & Nov & 37319 \\
\hline & $2080 \mathrm{~s}$ & Aug & Apr & 27650 & Nov & 37651 \\
\hline & $2020 s$ & Aug & May & 23169 & Nov & 34227 \\
\hline \multirow[t]{3}{*}{ A2 } & $2050 \mathrm{~s}$ & Aug & May & 23601 & Nov & 40156 \\
\hline & $2080 \mathrm{~s}$ & Aug & May & 33749 & Nov & 44179 \\
\hline & $2020 s$ & Aug & May & 18392 & Oct & 29713 \\
\hline \multirow[t]{2}{*}{$\mathrm{B} 1$} & $2050 \mathrm{~s}$ & Aug & May & 28293 & Oct & 43648 \\
\hline & 2080 s & Aug & May & 35364 & Oct & 53018 \\
\hline
\end{tabular}

From the table it is seen that the timing of flood peaks are likely to shift more often towards earlier month when compared to the observed condition. These changes in high flows can be explained by rising temperatures which cause earlier snowmelt in addition to the increased precipitation. As the temperature rises, more of the precipitation falls as rain and less water is stored as snow. Hence, the peaks tend to arrive in advance for the projected periods. For the same reason the variation of high flows for scenarios A1B and A2 are more rapid than scenario $\mathrm{B} 1$ due to greater increase in temperature. The steeper gradients of the rising and falling limbs for various scenarios indicate that the rate of change of flow is likely to be greater in contrast to current state of the river. For $\mathrm{B} 1$, the rate of change is maximum as floodwater is more concentrated within the shorter period of time compared to other scenarios.

The results of this study suggest that the flow regime of
Lower Meghna River has a stronger response to the increase of precipitation than to the increase of temperature, specially in the monsoon period. These results are consistent with the fact that the variation of precipitation increase is much greater than the temperature change during monsoon and the total volume increase in basin runoff is largely contributed by the precipitation other than the effect of evaporation and melting of glacier-snows. However, the impact of temperature and consequent evaporation becomes more pronounced in the dry periods.

\section{Conclusion}

The anticipated change in Ganges-Brahmaputra-Meghna (GBM) basin climate is likely to have a significant impact on its rivers, particularly on the lower riparian rivers like the Lower Meghna. The projected streamflows of the river, 
based on HadCM3 GCM, showed that the changes in basin climate tend to affect the timing and magnitude of peak flows as well as the high flow and low flow events at monthly or seasonal time scale resulting in dramatically altered flow regime. Observing the monthly projected flows of Lower Meghna River for different SRES scenarios and comparing with the observed condition, it was found that the peak flow may increase $4.5-39.1 \%$ in monsoon and the low flows may decrease $4.1-26.9 \%$ in dry season indicating high seasonality as a result of climate change. Seasonal variation of precipitation and temperature, i.e., excess precipitation in monsoon and lack of precipitation along with higher temperature in the dry season also affects the timing of peak, onset and recession of flooding. The flood peaks are likely to shift towards earlier months and the rate of change of flows during the rising and recession of floodwaters are likely to be much higher compared to current state of the river.

The results of the study also indicate the exacerbation of flooding potential, particularly during monsoon due to the largest increase of peak flow in August-September. In monsoon, the confluences between the Brahmaputra and the Ganges (known as the Padma) and the Meghna become two huge water pools. Due to climate change, the projected increase in Lower Meghna River flow depicts a critical situation where the synchronization of peak flows of the major rivers will induce severe floods of high intensity, particularly in the central part of Bangladesh. Changes in various components of flow regime such as the timing of onset, peak and recession will also affect the pattern, intensity and duration of such floods. The situation may become worse if it is associated with global warming accelerated sea level rise[18].

Since similar trends of flows appear for all the three scenarios A1B, A2 and B1, the results of the present study are quite indicative about the alterations of flow regime and high flow-low flow events of the river due to climate change. However, substantial uncertainty lies in the magnitude of projected streamflows which is primarily associated with GCM structure, magnitude of global warming, emission scenarios and response of regional climate to the global climate. Proper selection of scenarios, sufficient understanding of the basin processes and careful training and validation of the model can reduce these uncertainties considerably. Although this is a single GCM, single impact model study, this has important implications for the indicative and qualitative assessments of the response of flow regime of GBM rivers to climate change. The impact such responses of rivers, particularly the floods or droughts, can be managed through regional cooperation among the concerned countries, long term basin wide planning and sustainable management of water resources of the basin. The type of analyses reported here can provide the planners and managers with the information they need to make evidence-based decisions about meeting demands for water resources, managing flood risks and protecting socio-economic and environmental balance of the basin in future.

\section{Acknowledgements}

The author is thankful to IPCC Data Distribution Center (DDC; http//www.ipcc-data.org), Climate Research Unit (CRU; http//www.cru.uea.ac.uk) and Bangladesh Water Development Board (BWDB) for providing necessary data to carry out this research work.

\section{References}

[1] B. Malmqvist and S. Rundle, "Threats to the Running Water Ecosystem of the World", Environmental Conservation, vol. 29, pp. 134-153, 2002.

[2] IPCC, "Climate Change 2007: The Physical Science Basis", Contribution of Working Group I to the Fourth Assessment Report of the Intergovernmental Panel on Climate Change[Solomon, S., D. Qin, M. Manning, Z. Chen, M. Marquis, K.B. Averyt, M. Tignor and H.L. Miller (eds.)]. Cambridge University Press, Cambridge, United Kingdom and New York, NY, USA, 2007.

[3] C. A. Gibson, J. L. Meyer, N. L. Poff, L. E. Hay and A. Georgakakos, "Flow Regime Alterations Under Changing Climate in Two River Basins: Implications for Freshwater Ecosystems", River Research and Applications, vol. 21, pp. 849-864, 2005.

[4] F. H. Verhoog, "Impact of Climate Change on the Morphology of River Basins", Proceedings of the Vancouver Symposium, IAHS, Publ. no. 168, 1987.

[5] CCC, "Impact Assessment of Climate Change and Sea Level Rise on Monsoon Flooding", Report Prepared by Climate Change Cell, DoE, MoEF; Component 4b, CDMP, MoFDM, Dhaka, 2009.

[6] M. R. Chowdhury and N. Ward, "Hydro-Meteorological Variability in the Greater Ganges-Brahmaputra-Meghna Basins", International Journal of Climatology, vol. 24, pp. 1495-1508, 2004.

[7] Ministry of Water Resources (MoWR), "Hydro-Morphological Dynamics of the Meghna Estuary", Report Prepared by DHV Consultants, Bangladesh Water Development Board, Bangladesh, 2001.

[8] A. K. Gain, W. W. Immerzeel, F. C. Sperna-Weiland and M. F. P. Bierkens, "Impact of Climate Change on the Stream Flow of Lower Brahmaputra: Trends in High and Low Flows Based on Discharge Weighted Ensemble Modeling", Hydrology and Earth System Sciences Discussion, vol. 8, pp. 365-390, 2011.

[9] M. Q. Mirza, R. A. Warrick, N. J. Ericksen, and G. J. Kenny, "Trends And Persistence in Precipitation in The Ganges, Brahmaputra and Meghna River Basins" Hydrological Sciences, vol. 43, no 6, pp. 845-858, 1998.

[10] N. Nakicenovic et al., "Emissions Scenarios", Special Report of Working Group III of the Intergovernmental Panel on Climate Change, Cambridge University Press, Cambridge, UK and New York, NY, USA, 2000.

[11] T. Mitchell and P. Jones, "An Improved Method of 
Constructing a Database of Monthly Climate Observations and Associated High-Resolution Grids", International Journal of Climatology, vol. 25, pp. 693-712, 2005.

[12] United States Geological Survey (USGS), "HYDRO1k Elevation Derivative Database - Asia", Distributed by the Land Processes Distributed Active Archive Center (LP DAAC) located at the USGS EROS Data Centre, from http://LPDAAC.usgs.gov, 2001.

[13] O. Kişi, "River Flow Modeling Using Artificial Neural Networks", Journal of Hydrologic Engineering, vol. 9, no. 1, pp. 60-63, 2004.

[14] J. S. Wu, J. Han, S. Annambhotla and S. Bryant, "Artificial Neural Networks for Forecasting Watershed Runoff and Stream Flows." Journal of Hydrologic Engineering, vol. 10, no. 3, pp. 216-222, 2005.
[15] X. Chen,J. Wu and Q. Hu, "Simulation of Climate Change Impacts on Streamflow in the Bosten Lake Basin Using an Artificial Neural Network Model", Journal of Hydrologic Engineering, vol. 13, no. 3, pp 180-183, 2008.

[16] ASCE Task Committee, "Artificial Neural Networks in Hydrology I.” Journal of Hydrologic Engineering, vol. 5, no. 2, pp. 115-123, 2000.

[17] ASCE Task Committee, "Artificial Neural Networks in Hydrology II.” Journal of Hydrologic Engineering, vol. 5, no. 2, pp. 124-137, 2000.

[18] M. A. Matin and R. Kamal, "Impact of Climate Change on River System", Proceedings of the International Symposium on Environmental Degradation and Sustainable Development (ISEDSD-2010), Dhaka, Bangladesh, pp.61-65, 2010. 